\title{
Emerging Urban Forms
}

\author{
JOS BOSMAN \\ Columbia University, USA \\ BRIAN CARTER \\ University of Michigan, USA
}

Jos Bosman is a native of the Netherlands who has been intensely researching modernism for the past twenty years. From 1981 to 1986 he was a fellow of the Dutch Architectural Institute. After teaching at the ETH for seven years he received teaching postions at Columbia and Yale, where he taught art, theory, criticism and dealt with issues of urban design and how to assess the emerging form of power, how you perceive power in the nature of piles, and urban piles specifically. In Switzerland he collaborated with others on various exhibitions and publications on Siegfried Giedion, CIAM, and Le Corbusier, and also has been curator of the CIAM Archives. Bosman's writings have appeared in numerous magazines and he is currently teaching art theory and urbanism. His discussion concerns a very peculiar and very interesting view that goes beyond our notions of topology and type and how cities come together as conglomerates of all these different figure elements.

Joseph Rykwert held a lecture in Zurich five or six years ago in which he posed the question "is the city an object or a field." This question seems to be answered very easily: when the buildings are high and standing next to one another like in Manhattan, it looks like an object; when you look to many post war extensions that were prepared in response to a lot of propaganda by the modern movement in Europe, it looks more like a field. For my generation, which was educated in the 1970 's, this kind of doubleness of object and fields has doubled again. You must know that Joseph Rykwert, when he poses this question, thinks of the Unité d'Habitation of Le Corbusier and the way Colin Rowe crticized it as an object, and he is on the side of the Smithsons and other younger people, who tried as architects to link these slab-like forms in networks that looked more like a field.

So object and fields are opposed in a way that died after Jane Jacobs wrote her very important and especially influential book that convinced a lot of colleagues that modern architecture should be considered to be dead for a while. After that Aldo Rossi, and the texture of his buildings looks very much like the old Manhattan buildings at the beginning of the century, reintroduced the city consciously as an object.

For me being educated in the 70's it's interesting how the idea of the city as an object was followed in the last years by a new notion of the city as a field by especially Rem Koolhaas, and his exhibition in the Museum of Modern Arts last February may be reintroduced to think about it in the larger scale in the United States.

All these things come on top of each other, and like most of you I arrived on the airplane here in Lisbon, and one of the things you think about when you arrive is, what am I seeing? You recognize some type of buildings that you know from other cities, but you have not been here before. You notice some modernist types that dominate, but it's not the organized, modern city; it's also not the historical city. It's something else. And that something else is probably a condition that is built in a symbolic way in every view, but that is characteristic of most cities and, for my part, I'm most interested in these areas, which are the largest of post-war planning. You have to deal with them and you have to deal with them again. I took, last year, some of the spots in Manhattan in which these type of forms were introduced for the first time, in the large super blocks of Paul Lester Weiner near New York University housing and the buildings by Pei next to Third Avenue; I'll talk about that a little bit later on.

One of the ways to deal with this whole problem in the postwar era is always to refer to Le Corbusier's proposals for the city, and one would say that he would have preferred these new forms. But there's always the question ... to what degree is form essential here? Is it the new form that makes the new city, the new architectural form, or are we dealing here with a condition in which the road is taken in another place. Because Hermann Jansen, a very important town planner in the late twenties, came with a Dutch proposal for the German city. You see the highways and the crossing patterns that were very similar to the Le Corbusier proposal. You see the opposition of traditional architecture and modern architecture doesn't work here because the traditional architecture can very well take that role. It's also the confusion that the actual city often represents that these things interfere, that in the process of thinking about the city, before the Second World War, the highway in Germany..the new monumental buildings..all that was considered to be part of the new future city. The most important theoretical personalities, repro- 
duced this as one vision after the Second World War. Because of the Holocaust, taking a part in history that asked for who was guilty and who was not guilty, we only looked at the modern-looking forms as the reference to write history and to understand what happened in the 20th century.

Today, and Colin Rowe was one of the first to introduce this word collage in relationship to the city, we like to refer to advertisements, chaotic images, as a contradiction to the modernist view. And in the case of Rowe there is already this confusion that it is not clear how, when he hates modernism, how he can like this, because these images come from books in which, for a very clear purpose, chaos was illustrated in order to make propaganda for a classical form of city planning.

This is from the book of Paul Schultze-Naumburg, in his book, Art and Race, from which Adolf Hitler took this notion of degenerate art. And this was degenerated city. This was one of the lost images. So this was bad, and what he liked was classical principals in town planning. The right one was used by Hegemann, who shares exactly the same ideal in this time period. And this ideal looked like the proposals of Loos for Vienna and Van Eesteren in Berlin. It's a competition entry from 1925. One of my students put it in the computer because you see there is it colonnade with a tower. That is the image that had to link the Brandenburger Tor and the former palace. From the air, it looked liked a modernist vision, but when you read carefully the things that Hegemann was saying, under these drawings, because he, and the jury for this competition, insisted very much to give this the first prize; he says, "we gave him the first prize because from the street you cannot see these buildings." And everybody always thought that this was the introduction and the way modernism won for the first time a real competition, in contrast to Le Corbusier, who did not and could not.

The contrast to that classical vision (it's always difficult to use these words, but let's call the Autobahn for a moment classical) were images like where the little train in Zurich that brings you to the central building shows in the cityscape the vocabulary of the engineer. My countryman, Mart Stam, a young architect who came from Berlin, who used this very train, applicated a proposal for Amsterdam, quite directly opposite to the Royal Palace, so it was conscious provocation. So it's also a kind of anecdote in an historical context that a building that looks modern can adapt very well in historical motif but it is not historical architecture, it is a building as old as the Eiffel Tower.

It is a topic to what degree we show and articulate traffic in our cities. This was consciously contrasted during the 1940s. What is strange, however, is that in the notion of modernism itself after the war, it was not so much this unstable or funny or experimental aura that continues, but in the way countries like Great Britain and English became the main language after the Second World War in these meetings of European architects, they tried to convince in a completely different manner as compared to before the war. And so the whole notion of infrastructure and the notion of stability becomes part of the notion of how to make a city.
This is from a book of Maxwell Fry, and he is also one of the teachers of the A-School where he received the same kind of connection of infrastructure, roads like the one here, and buildings, which is the type of language that is known afterwards as Team Ten. Again, it was practice, and mainly the practice in the American city, that examples like this became criticized, as in the books of Colin Rowe. I found this advertisement in an Architectural Record of the 1950s; Le Corbusier made this sketch: "Now in the end, office towers in the park." It means those who pleaded for modern architecture for the first time admitted there are interesting examples, but as soon as the form is badly articulated, it suddenly creates a bad city. This was the way it was commented on in the time itself.

And this is probably a question you cannot put out strongly enough: to what degree articulation is again a point to convince. Because in this polarity of thinking of the city as an object or a field, many who design like Rem Koolhaas often argue that their way of presenting, dealing with program, and so on is not about articulation; this is not important, it's the other position. And the strange thing is that by doing that a lot of modern architecture has been recycled in recent years. So, for instance, the library in Paris, the new national library, takes a completely Le Corbusien notion of the towers that form a group, there in a more classical way that you can also read in this contemporary view. It's probably only because of the articulation of the facade that one could discuss the quality of this complex.

But, that stops about there, this modern architecture after the late 1960s. Now Rem Koolhaas in EuroLille gives substance to what was only a drawing in the 1950s; an image of these concrete levels with buildings on top. Its a completely unknown drawing that I found in the archives in Zurich, but it's not unimportant because it's student work shown at the first meeting where Team Ten members met in order to find out what strategy for the city they wanted to research. This was in 1955. And this image of EuroLille of Rem Koolhaas resembles very directly that of the Smithsons for Berlin. And topics that were there in the 1970s in order to show how the city was destructed, you mostly don't find in libraries because it is a topic that was not seriously taken because it was antiarchitecture, it was a protest against architecture. Today, it comes back into architecture again in the example Rem Koolhaas. He is so much intrigued by the cityscape that produces this kind of force that he even incorporates them in building complexes. I found this parking lot in Atlanta that resembles very much what Koolhaas designed for Karlsruhe, so it means it would be very interesting to study Atlanta much more precisely instead of only talking about the ideas behind it. To look at examples and the way they are used, and to question, to what degree this brings new quality.

I found a drawing in an obscure East European magazine of the 1940s in which a diagram of Los Angeles was presented with its traffic pattern. Modernist architects would be scared to see this image and it would convince them to make more space in the city. I think Koolhaas was one of the 
the first who would redesign this as an interesting architectural object in itself. So it is a reversal of seeing what is considered normally to be banal and aside from what we have to take seriously as a profession, and to take that as the material to shape architecture.

It means that projects like EuroLille, of course, also has its reality in Paris that is exactly the same program only it is not a cheap TGV crossing it, but it lies next to the Place Italie: I found this when I went to find new film photographing the library, so it is not known by any well-known name, but you see the same type of shopping center, it was built on the same scale and it was finished on exactly the same date. So it means when you don't want to discuss architectural articulation, the debate has stopped here. So we have to define what is then architecturally more particular in EuroLille as compared to this project in Paris. Reality in Paris looks like the tower I discussed near the beginning, near completion last year. So suddenly, there was a debate about the city stopping the acceptance of modern forms in the 1960s. In a way the themes are recycled. Ask for a judgment that really deals not only with the intention but also with the architectural articulation. And the question of what kind of cityscape is created here.

Koolhaas explains, in a film that was shown in the Museum of Modern Art, how as one leaves the station in EuroLille you are opened to the shopping center and here you see how this looks in reality. This kind of view is of course related to many examples in architectural history. It's like a baroque type of experience. From one point, your view is open towards the other one which only in the way it is formally articulated brings in the notion of the end of the twentieth century. I would argue it's comparable with the Japanese type of motorcycles that, in contrast to automobiles and other machines at the beginning of the century that always tried or strained to leave the earth, that at the end of century, high speed machines tend to express that they search the relation with the earth again. We seem to deal with how to arrive and not how to leave. Which is a position that I tried myself to make more extreme in my own studio. I think that today the reality of the city is coming much closer to the surface of the earth and that it is there that the new type of articulation could be examined in more detail, both on a programmatic level and on an architectural level.

The interesting point one arrives at at that moment is that when we realize that most of the new environment is realized after the Second World War, especially in the 60 s and the 70 s, that in the way these towers are placed next to one another, as in the case of the early works of Pei in Philadelphia, they express a cosmic ideal of the time period. In contrast to the earlier period in the 1920 s where Giedion derived understandings like space time, which were referring to certain notions of science, in the $1950 \mathrm{~s}$, there came this notion of the expanding universe, and many architects, like Pei in the case above, tried to place buildings that come with this notion of expanding. This example shows, however, the problem that arose when the same three buildings, I mean the same design, were plugged into Manhattan a couple of years later for the university housing. And it is there that the system doesn't work anymore, where you are narrowed in by Manhattan. Those who criticized it, as well as those who liked it, never dealt with these problematic examples; they always looked at the most ideal example behind it. The reality of the city is of course this: the latter project is standing next to two large super blocks by Paul Lester Weiner. Pei was clever enough that he did not want to repeat it one time, but this was not enough to make a relation with Soho lying behind it.

My own students first had the reaction like probably everybody would have, that is, to attack the towers. I tried to bring them more to the ground and to take those shopping malls that were placed next to these towers in order to respond to the criticism of modern architecture after the $60 \mathrm{~s}$; it looks like they are ashamed of this open space behind it. But it means that you cannot take and enjoy the open space as a quality. It's only a kind of empty hole when you arrive behind it. So, in one of the student proposals for this side of the tower there is a space hollowed out for a market space. In front of these towers would come a terrace with shopping under it, and towards one side it folds down with a market space. It means that you have to become creative in how to deal with the presence of this kind of open space and trying to differentiate it, rather than just putting new objects in between. You see, the whole condition is that of the city as a field and objects standing on top, but it's exactly there where they meet that you have to develop new ideas - where you have to concentrate with your desire.

I think that there's a tendency in the work of the students which different opinions about architectural education today tend to oppose, and one says only the program is important and the other says we have the responsibility for the new objects. What I try to show with my presentation today is that we have a responsibility for the existing city that asks for a way of intervening that tries to avoid making new objects in between places like Pei created in the example above. It was a big debate also last year, what to do with areas like Kips Bay. I explored the sites in a way that we should not make the mistake to simply fill them up with new objects, but the way they are forced into the grid of Manhattan leaves a lot of possibility to act at the edges of them. One way in dealing with that part of the city is trying to redefine the surface in a way that it is ambivalent in opening and closing off the space.

In conclusion, I think that this notion of the object and the field, in my case, makes it possible to read images in a new way. After the war, this type of image was read by historians as a criticism of severe cubism, which is completely in the line of saying severe functionalism is bad. You need another attitude. But, I think in this case, we come to a point where we don't only talk about intentions, but try to read how such a picture is made. And it's this kind of exercise that I have tried out here in order to make this statement. I think with that statement, also, the old, well-known examples, like Pei's Society Hill in Philadelphia, will get their meaning again, but not as an isolated one, but one that can learn how to articulate in this kind of fabric that we have to deal with as a whole. 
Brian Carter hails from the realm of high-tech and is currently chairman of the Department of Architecture at the University of Michigan. He was formerly with Arup Associates, and he worked closely with Peter Rice, with Arup Engineers. At Arup Associates, Professor Carter worked in multi-disciplinary teams on a wide range of architectural and civic projects. In addition to his professional experience, he has taught at the University of Bristol, the University of California Berkeley, the University of Liverpool, the Royal Academy in Copenhagen, the Rhode Island School of Design, and he is an associate of the RIBA and a fellow of the Royal Society of Arts. He has served the Royal Institute of British Architects in many capacities: as assessor, external examiner, juror in design competition and awards. His writings have appeared in internationally published books and journals, including the widely recognized Architectural Review, where he has served as a guest editor and Architecture, formerly the AIA Journal. Professor Carter has also curated a number of exhibitions, including the celebrated exhibit on the work of the RIBA Gold Medalist, Peter Rice, and he is now involved with urban planning.

I wanted to take the theme of the conference, the discussion about accelerating changes in the geography of power, and really talk about that relative to work in practice.

Accelerating changes in the geography of power are creating an increasingly global culture. International capitalism is shaping a mass culture which is becoming more and more general and as we heard from our first speaker, perhaps more and more predominate. In fact, if people in cultures are defined by the balance that they strike between the general and the particular, than it's becoming increasingly possible to argue that in Western society today, that balance is in real jeopardy. Architecture has an important role to play in this context, for it can be counterbalanced to the increasingly general aspect of other parts of our culture. Of all of the arts, it is architecture which is most capable of convincingly addressing the issues of the particular. Issues of place, climate, materials, constructional technique, history, and social setting, to name only a few.

Last week, I met with the bassiuer of a Cambridge College, and in speaking to him of projects for graduate accommodation, which is currently under construction there, he emphasized the need for the new building to be designed to last for at least 500 years. His comments, although perhaps a little unusual in this day and age, emphasized the significance of building and that most have a life expectancy which exceeds that of their architects. It emphasizes that architecture should not merely entertain in the way that the media industry increasingly, perhaps, suggests that it should. But rather that it is current concerned with reality and not with virtual reality.

As a consequence, people feel an enormous responsibility for the built environment, and perhaps more than anything else, architecture represents the legacy of our time. It is these concerns regarding the balance between the general and particular, together with the consideration about the architecture of our time, that I'd like to talk about briefly this morning.

The changing geography of power has tended to create both the opportunities for architects to be involved with the design of larger and more complex projects, and for those designs to be realized. Engineers, cost estimators, energy advisors, environmental consultants, traffic planners, and the rest, are increasingly vital members of a group of designers, yet are often seen by architects as actually reducing and undermining the soaring ideas that they may have just by the calculated application of reason. I am, of course, being quite unreasonable in suggesting these perceptions of the profession, and by the profession, but they seem to be increasingly important and particularly critical issues for architecture, if as a profession, it is not merely to become a convenient arm of the real estate business.

Just as the spirit of collaboration seems important in the development of modern architecture, so will an increasing emphasis on both the size of development projects and the speed of their realization. Architecture is inevitably shaped by industry. The power and the authority of the construction industry should not be underestimated. In many ways, of course, it is necessary to implement what we might loosely categorize as the emerging urban forms, suggested by the title of this morning's session. In projects like Broadgate, Stockly Park, EuroLille, Battery Park in New York or the Expo, which is planned for Lisbon in the very near future, all depend on industry and that authority and strength of industry. However, it is critical that projects also provide opportunities for exploration, for it is in that act of exploration that designers can find the enjoyment, originality, and simplicity which, because the outcome in unpredictable, is a necessary part of communicating with the public at large.

It is important that the process of making architecture is not dominated by industry. People need to see the connection between what is built and the people who built it. Invariably, in looking in the things of the past which we all enjoy, and I'm sure there are a lot of those on our walking tours which are in our package, but whether they're the the Gothic cathedral, the Victorian railway station, or the historic city, the evidence of the people who built is obvious. I believe that as designers it's important to retain this trace of the hand. It is important for people not to become alienated from their surroundings. And I think that that trace of the hand and the connection with the people who make the buildings and the people who design the buildings is a very, very important part of that.

An interest in materials and their inherent qualities and ever increasing potential, is important for industry. But for architects and their colleagues in the design team, it presents a vital design stimulus which can provide a critical contact between people and the buildings that we design and others build. This exploration of materials is not new and it has a very, very distinguished history. If we think about Brunelleschi and his work on the splendid dome of the 
Florence Cathedral and his consideration of the material and the way the building was built, or Paxton and his work on the Crystal Palace, or perhaps more recently, and in the United States, the work of people like Charles Eames, and Eero Saarinen, in looking at the materials and use of materials in ply, in metal, and in glass, there is a very, very significant tradition to this exploration of materials. And oddly, and I mentioned specifically the relationship to people like Eames and Saarinen, because I think in many conversations I've had in the brief time that I've been in America, a lot of that interest is dismissed very quickly as being European. And I think that there is a very fine tradition in the United States and perhaps it's a tradition that is somewhat ignored in the more recent past, but I think that there is nonetheless a very important tradition there.

I think that exploration of materials and design can take in both the new and the old. Stone and masonry have their place, as do glass and fabric and steel. And all benefit from the inquiring mind of designer and the influence that he or she can bring to bear on industry and the manufacturing process. In commenting on the design of Centre Pompidou, Peter [Rice] writes, perhaps best summarized in significance of such an exploration of material and design, when he observed the use of cast steel. And I'd just like to read a quote from Peter's book. This is talking specifically about Centre Pompidou:

Its extensive use of cast steel, an early industrial product still much in use today, is an attempt to introduce a material into building construction to change the way building is perceived. It is an example of the use of new materials to change the feeling and scale of a large monumental building.

The piazza facade of this building has nothing to decorate it but structural elements. By using the castings as the main building joints, the shapes and forms were liberated from the standard industrial language. The public could see the individual design preference. Modern computers and analysis techniques and modern testing methods made this possible and we were back to the freedom of our Victorian forefathers. The individual details were exploited to give a personal design philosophy full reign, and the final design was, of course, the work of more than one person. Many architects, engineers, and craftsmen at the foundry contributed to the actual shape of each piece. And each piece was subjected to the rigors of detailed structural analysis to ensure that it was fit for its purpose in every way, and this too influenced the shape and final configuration. The pieces are indeed better for all the different expertise which went into their make up. They are more logical, more self-evidently correct in their form. They require people to look and perceive so that they may understand.

This brings to mind another myth about technology. The feeling that technological choice is always the result of predetermined logic. The feeling that their is a correct solution to a technical question is very common. But a technical solution, like any other decision, is a moment in time. It is not definitive. The decision is the result of a complex process where a lot of information is analyzed and examined, and choices made on the evidence. It is a moment in time and place, where the people, their background, and their talent is paramount. What is often missing is the evidence of human intervention. So, by looking at new materials, or at old materials in a new way, we change the rules and people become visible again.

I just wanted to talk about three projects, and I'd like to show slides of three projects. And talk about those projects just from the point of view of the issue about the exploration of materials and the collaboration of the disciplines in design, and I wanted to start off with a few slides of a very, very recently completed project in England.

\section{INLAND REVENUE HEADQUARTERS}

This project is especially interesting to me because not only is it close the place where I grew up and went to school, as mentioned this morning in Nottingham, but it's also a project which, as an architect, I worked on one of the alternative proposals for the competition. So, it was an invited competition for a new headquarters for the Inland Revenue. And six practices were invited to work on the design of this project. It's England's answer to the IRS and just being built on a site in the city close to the center and alongside Nottingham Castle. It perhaps maintains a certain spirit of Robin Hood about it as a project, because it does seem to me to capture some of the inevitable corporate wealth of the headquarters office building, which Saska Sasen touched on this morning. An attempt in a way to give it back to the citizenry at large. The project is for an office development for 1,800 people. It's on a large site banded by a canal and very close to the castle, which is on a rock. And one thing which I'd really like to focus on there is the site planning strategy. The winning proposal by Michael Hopkins, which is the building that's just being completed, chose to divide that building up, into a series of buildings. So instead of being a corporate headquarters, it was actually a series of six buildings and the amenities were planned in a seventh building. And those buildings were actually made as buildings which were on the street. And so there was a whole grid of streets which separated those buildings. And so as such, the scheme was very particular in typing to knit the development back into the fabric of the city and make, instead of one corporate headquarters building, which I must confess was the design proposal that was put forward from our own office, a series of individual buildings here which are separated by public space.

As a big site in the city, you can see on the model figure the relationship of the site to the castle and to the canal so that the canal is here and the castle is here on top of the hill. So there was an idea here about not only dividing the development up into a series of block, but also designing the streets so that it maintains the views of the castle, which is very 
important from other parts of the city. And you can see here the blocks themselves were designed as courtyard buildings for the most part, so that they were actually defining the space for the office staff who are working in each of those buildings.

Nottingham is an industrial city which is largely built up in the center, or was, with a series of red brick industrial buildings, which were Victorian buildings. And buildings that were four or five stories tall, built about 150 years ago and perhaps best typified by J. M. Richards, in his book, The Function Of Tradition. And in an inspired move, the designers devised this site plan which not only avoided obliterating the history of the city, but also seems to have drawn inspiration from the historical patterns of building. The project divides the headquarters into a series of distinct buildings, and in doing so wins back a piece of the city by creating this network of public streets. The streets, which responded to one of the conditions of the competition to provide these views of the castle, also at the same time, link the development into the city. And provided spaces that traditionally streets provided in the historic city. So it becomes places for pedestrians to walk, places for people in the city who didn't work here to take shortcuts through the city. Tree lined public spaces for people to stand and chat at lunchtime, and also places to park care. And so the ubiquitous parking garage disappears and parking reappears where it belongs, on the street. The buildings are all low rise buildings relatively shallow and planned to be open to the street. While it's enclosing the more private landscape courtyards within, or containing the space between the right angle buildings as you can see.

I just wanted to talk very briefly about the design of the building and because in some way the site planning strategy is very, very important in this scheme I think. And perhaps best illustrates how a scheme can be a new piece of a city without obliterating the city. But the scheme is also very interesting from the point of view of the collaboration, as I just discussed. And the development of the structural systems and mechanical systems and ideas about the environment seem to be an integral part of the architectural design of this project. And I do feel that that's very, very important for the profession. Otherwise, I think, as a profession, we end up designing the last two inches of the external skin of the building, and very, very little else if we don't take an interest in these others issues. So the office buildings themselves, as I said, are low rise, relatively shallow, and planned to open onto the street. They also are planned to use traditional materials so they used red brick, which is familiar in the area, and glass in a way that makes the building not only quick to build, but thoughtful in its appearance and in the way that it used natural daylight and ventilation within the buildings. The office buildings themselves are 13.6 meters deep, instead of the traditional 18 meter deep developer building, and the reason for that is because 13.6 meters allows you to provide natural ventilation. So the office spaces themselves are all naturally ventilated and also they have very, very high levels of natural lighting.
The brick piers which support the concrete vaulted structures and the structure is completely exposed internally and was prefabricated off site, and the building was built very quickly. And so the actual construction of the building really defines the design and you can see that there are some screening systems to deal with the problem of buildings which need to have substantial glazed areas but also need to limit the solar gain.

And so the elevation is made by some of those responses to the environment. So for instance, there are a series of glazed areas here in which the glass is mirrored on the top surface and fitted on the bottom and so they act as a sunscreen for the glazing and the windows open so this becomes a handrail to protect the people when the windows are open. But it also acts as a sunscreen to the external. So there is a reconciliation there about the problems of how to design an office building that needs to be heavily glazed, but also is sensitive in the way that it used energy. And in that respect the circular tower occurs at each corner of the scheme. It includes the staircases. It's made of glass block and it actually acts as a natural chimney to induce natural ventilation and the flow of air through the building. And this curious little saucer on top here goes up and down in a great British, Keith Robinson sort of tradition for different times of the year. So that in the summertime, when it gets very hot, the fact that the staircase tower is made of glass block, it warms up, the lid pops open and so the draft is induced through the building as a whole.

So the considered patterns of the elevation is a response to those conflicting requirements of the glazed building and an energy conserving building and also of a building that somehow belongs to this place and is particular and isn't general. And in a way, it doesn't make those references to familiar historic precedents by resorting to references to forms of the past. For instance, buildings that look like pagodas because they are in China. The distinction between work space and amenity buildings, the amenity facilities in this building, it is the workplace for 1,800 people.

The buildings were actually opened formally in April this year and tree-lined boulevards along those streets now which provide additional screening and/or both to the car and to the external wall. And here you see that the amenity building itself, which in the vein of city building, is designed perhaps in a rather extreme fashion, but to be expressed as a different sort of building from the surrounding office buildings of the development. And this has the restaurant facilities and the social facilities for the offices and the main reception in this forecourt here. In the center there is also a covered football pitch, an indoor football pitch, for the staff here. So that it actually isn't too bad working for Inland Revenue after all. Why I always thought all these years it was a rather terrible place to work, but this changes my view certainly. And the other end of that fabric structure building fronts onto the canal and looks to the castle.

So, I just wanted to emphasize in that building that in a sense the site development strategy I think is very, very 
significant in terms of the interpretation of what a corporate office building might be like. And what a corporate office building might be like in this place.

There is one other thread to that argument which may be interesting and relevant to mention in terms of Saskia Sassen's comment this morning. But one of the requirements, or one of the discussion points which came up in the development of this project, was that because of the system being so volatile, and because of the mechanization of work, and the fact that the workforce may get bigger or smaller, and also the pattern of investment on buildings like this, was increasingly taking a form where people were uncertain about what the future would be like. One of the bonuses of this strategy is that the actual buildings can be used by other tenants. So that there is something there which normally for an architect, I think, would be a problem if a client said they wanted to have that option. But in this particular scheme, it seems to have been used to some advantage in the design I think.

\section{CENTRE POMPIDOU}

I mentioned briefly already the Centre Pompidou in the exploration of materials and the next few slides just seek to underline that and to look at the way that that material was used in that building, which is now quite an old building of course. On the left is the slide of the winning competition by Richard Rogers and Renzo Piano, which Peter Rice was incredibly involved in. But you can see in that model that the idea about the structure at that stage is very, very notional.

But there was an idea in the scheme which is embodied in the section growing on the right of this very large series of flexible spaces. The structural idea was developed so that long span structures gave you those column free spaces for that magical quality of flexibilities so loved at the time. And that out of that the structural system with the long span structure and the cast steel jaborats to reduce the bending moment on the column and to reduce the depth for the structural spanning member on the large open floors, was developed. The drawing on the left fixed over the column and picking up the long span truss there, and on the right hand side, a photograph which was taken in the crafts steel work, where as you probably know, the original proposal was tendered by French contractors, who said that it wasn't at all possible to make anything like that. But they could come up with something which would look like that but not be made in cast steel. And just before that, Peter Rice and a number of his colleagues had been in Osaka at the expo fair and seen quite elaborate castings. And they were in touch with both Japanese subcontractors and with other European subcontractors and eventually after long discussion and series of discussions, the project was re-tendered and Crops were the winning tenderer. And so the slide on the right is actually taken in the foundry when these cast steel jaborats were actually just being fabricated.

Really addressing that point about the making of things and how they're put together and legibility of the system and on this particular project of course, that issue became something of a fetish I think. It was that particular attention to detail that Peter was very, very interested in, and I just wanted to read a little bit from his talk at the RIBA when he was awarded the Gold Medal:

At the time of the Pompidou Center, I had one very gratifying moment. We were building the steel structure and I was very concerned that the scale of the building and nature and face of it would be intimidating. When people look at things, they carry with them prior prejudices and when you build a steel building, all the other steel buildings that people have seen become part of the way they react to what they are looking at. It was then that I conceived the idea of introducing the cast steel because I wanted to break some of those prior prejudices and produce something which would be unexpected, and being unexpected, could challenge people to look at it. One day, nine months after the building was complete, I saw an old lady, just like the old ladies who my mother knew in Ireland, dressed in black, sitting on the forefloor with her hand on the jaborat (one of the big cast brackets which you put around the columns), just looking at it. I thought that by introducing elements like that we could make people who would normally be alienated by things, comfortable.

He goes on to talk about, he watched this particular group of people at the building. But I think there is a very great concern in the buildings that Peter worked on and some of the other buildings that I think are interesting for the profession to look at, about the actual assembly of buildings. And I think that in terms of the discussion of the general and the particular, often buildings are put together in a very general way and there isn't that attention to the detail, which I think is very, very important.

\section{KANSAI AIRPORT}

I just wanted to close with just a few slides of Kansai, the airport which was designed by Renzo Piano following his successful competition entry in 1988. And I wanted to talk about this because I really wanted to draw attention again to issue about collaboration. Renzo Piano and Peter Rice and a man called Tom Barker, who is a mechanical engineer, were very involved in the development of the competition scheme for Kansai. And one of Renzo's particular interests was that this building would be very recognizable from the air - that it would have some suggestion of flight. And that also, it would be very clear for people who were going to use the building. The form of the building, consequently, took on this form with this very light, curving roof, with this long wing for the departures and arrivals.

I just wanted to talk about that very briefly because the idea you can see imbedded in this building, the main passenger building, which is this building here, so this 
section is taken through here and this is the wing. There was an idea here that, perhaps in contrast to the structure on Pompidou, that the structure here begins to take on a much more baroque quality. The design of the structure would be such that it would actually lead people through the building. It is quite interesting that if you look at it compared to Stanstead, for instance, that Stanstead in a sense is a very beautiful repetition of a single unit, but it isn't directional. One of the things that I think that they were very interested in this particular scheme was trying to use the shape of the space and the design of the structure in a way that would make the direction through the building for strangers coming to the airport for the first time, or for frequent travelers for that matter, much more direct. So, there is this long curving roof with a very directional structure, which is very clearly exposed, but which leads you through the building.

The funny blue tab pole on that drawing on the right hand side, is something which was developed in the design of the roof that, in creating this very, very large space, that the environmental design was something which was very important and it would be critical to make sure that that space wasn't cluttered up with mechanical and electrical impediments just servicing the space. So there was an idea which was developed in the design proposal that there would be macro environmental system with the big space and then there would be a micro environmental system which would be at the counters by those red boxes on the section. In looking at that, the span of that roof is 80 meters from column to column so it's a very big structure. The idea was that it would be possible to shape that roof in a way that it would entrain the air and you could blow the air from the macro environmental systems along that roof and the profile of the roof could be developed to help that entrainment of air so that the air was carried almost across the whole of that 80 meter span. So immediately there begins to be an integration between the architectural idea and the structural idea and the idea of how you condition the environment.
These are just a few slides which are from a whole series from a competition of fluid dynamics of the space. Looking of the profile of the roof and the way it would entrain the air at the different times and conditions throughout the year, and on the right hand side you see of the expression of that 80 meter triangular truss, and between each of those trusses, these fabric screens which help to entrain the air along that space. So the roof itself was beginning to work in a very, very broad way.

There are lots of very interesting technical aspects about this building. I think it's the world's longest building. It's 1.6 kilometers from one end of the wing to the other. And this is the view from the arrivals wing and you can see the expression of that structure on the right hand side. So it's just a glazed building on the arrival side and you can see that structure arching its way across the roof of the entire building and giving you a very, very clear sense of direction within the scheme.

\section{CONCLUSION}

It is with an emphasis on this spirit of collaboration and design and the importance of the particular and the reality of construction that I'd like to end my talk. As a profession, we are often seen as being remote and viewed with suspicion by the public. This may be an English view actually. Architects, it seems, have apparently almost single handedly transformed cities from busy city places to desolate spaces empty of life and love. They have made places to work which give you headaches, have sick building syndrome, and which are remote from amenities, and have also gone on to create hazards in suburban wastelands which are far from friends and neighbors. It seems that the product and the process have become seriously divorced and perhaps by working critically and more collaboratively, we can restore a balance between the general and the particular in architecture in a way which can help to confirm its value in our society. 